This is an electronic reprint of the original article. This reprint may differ from the original in pagination and typographic detail.

Author(s): Karhunen, Tommi; Välikangas, Juho; Torvela, Tiina; Lähde, Anna; Lassi, Ulla; Jokiniemi, Jorma

Title: $\quad$ Effect of doping and crystallite size on the electrochemical performance of Li4Ti5012

Year: $\quad 2016$

Version:

Please cite the original version:

Karhunen, T., Välikangas, J., Torvela, T., Lähde, A., Lassi, U., \& Jokiniemi, J. (2016).

Effect of doping and crystallite size on the electrochemical performance of

Li4Ti5012. Journal of Alloys and Compounds, 659, 132-137.

https://doi.org/10.1016/j.jallcom.2015.10.125

All material supplied via JYX is protected by copyright and other intellectual property rights, and duplication or sale of all or part of any of the repository collections is not permitted, except that material may be duplicated by you for your research use or educational purposes in electronic or print form. You must obtain permission for any other use. Electronic or print copies may not be offered, whether for sale or otherwise to anyone who is not an authorised user. 


\title{
Effect of doping and crystallite size on the electrochemical performance of $\mathrm{Li}_{4} \mathrm{Ti}_{5} \mathrm{O}_{12}$
}

\author{
Tommi Karhunen ${ }^{\mathrm{a}, *}$, Juho Välikangas ${ }^{\mathrm{b}}$, Tiina Torvela ${ }^{\mathrm{a}}$, Anna Lähde ${ }^{\mathrm{a}}$, Ulla \\ Lassi $^{\mathrm{b}, \mathrm{c}}$, Jorma Jokiniemi ${ }^{\mathrm{a}}$ \\ ${ }^{a}$ University of Eastern Finland, Fine Particle and Aerosol Technology Laboratory, \\ P.O.Box 1627, FI-70211 Kuopio, Finland \\ ${ }^{b}$ University of Jyväskyla, Kokkola University Consortium Chydenius, \\ Talonpojankatu 2B, FI-67100 Kokkola, Finland \\ ${ }^{c}$ University of Oulu, Research Unit of Sustainable Chemistry, \\ P.O.Box 3000, FI-90014 Oulu, Finland
}

\begin{abstract}
Defect spinel phase lithium titanate $\left(\mathrm{Li}_{4} \mathrm{Ti}_{5} \mathrm{O}_{12}\right)$ has been suggested as a promising negative electrode material for next generation lithium ion batteries. Flame spray pyrolysis has been shown to be a viable fast, one-step process for synthesis of nanoparticulate $\mathrm{Li}_{4} \mathrm{Ti}_{5} \mathrm{O}_{12}$. However, due to the rapid quenching that is integral to the process the crystallite size remain very small and non-uniform.

To overcome this shortcoming a vertical flow tube furnace was used to increase the high-temperature residence time. This resulted in an increase in the crystallite size and crystallinity of the product. As a result of this increase the electrochemical performance of the $\mathrm{Li}_{4} \mathrm{Ti}_{5} \mathrm{O}_{12}$ was markedly improved.

Furthermore, silver doping of the $\mathrm{Li}_{4} \mathrm{Ti}_{5} \mathrm{O}_{12}$ material can be carried out simultaneously with its synthesis in the FSP process. The resulting nanosized silver particles on the surface of the $\mathrm{Li}_{4} \mathrm{Ti}_{5} \mathrm{O}_{12}$ particles further improve the electrochemical performance during high current operations.

The specific capacities of these high-temperature synthesised pure and silverdoped $\mathrm{Li}_{4} \mathrm{Ti}_{5} \mathrm{O}_{12}$ nanoparticles were found to increase by up to $6 \%$ and $19 \%$, respectively, compared to a commercial reference. Thus the technique provides a simple method for synthesising superior quality $\mathrm{Li}_{4} \mathrm{Ti}_{5} \mathrm{O}_{12}$ for battery appli-
\end{abstract}

*Correspondence to tommi.karhunen@uef.fi 
cations.

Keywords: Li-ion battery, Nanoparticles, Phase composition, Synthesis

\section{Introduction}

Concern over the worldwide carbon dioxide emissions, as well as the dwindling oil resources, have led to increasing interest in efficient energy storage solutions for both automotive and renewable energy supply applications. At

5 the same time advances in the miniaturization and mobility of consumer electronics are placing ever increasing pressure on the capabilities of rechargeable batteries.

Currently lithium ion batteries with their high energy density and number of charge cycles are, perhaps, the best available technology to meet these demands [1. However, for the widespread utilization of Li-ion batteries in high-demand applications such as full and hybrid electric vehicles, a number of improvements are still required. These include price, safety, specific energy and power, and the cycle life [2].

Lithium titanium oxide $\left(\mathrm{Li}_{4} \mathrm{Ti}_{5} \mathrm{O}_{12}\right.$, LTO $)$ is recognised as a promising material for the negative electrode of the next generation Li-ion batteries as it is low cost and safe, and has an excellent cycle life [2, 3. However, it also has a few drawbacks, the major one being its low electronic conductivity.

Two solutions for this problem have been proposed. First, reducing the primary particle size of the electrode materials reduces the length of the electron diffusion paths and the local current density [4]. The high-rate capabilities of electrodes made with LTO samples from different suppliers were studied by Kavan et al. [5]. They showed that the specific capacity fell off rapidly for very small crystallite size $(<20 \mathrm{~nm})$. The fall was attributed to a decrease in the Li-ion diffusion coefficient due to either a shrinking of the crystallite lattice or to increased $\mathrm{Li}^{+}-\mathrm{Li}^{+}$repulsion, or a combination thereof.

However, large primary particle size also leads to low active surface area and, thus, a decreased charge transfer rate between the electrode and the electrolyte. 
As such an optimal crystallite size range exist for LTO nanoparticles. This was reported by Kavan et al. [5] as 20-80 $\mathrm{nm}$.

Second, improved conductivity and rate capacity have been observed for LTO doped with transition metals such as silver [6] or copper [7. However, the standard LTO production method of solid-state chemical reactions typically produces LTO particles with a diameter on the order of $1 \mu \mathrm{m}$ and the doping often requires a separate process thus adding to the complexity, and consequently 35 to the cost, of production.

Single-step gas phase processes are more efficient than the solid-state ones in both the energy and raw materials required which is of great importance when scaling the process up to industrial scale. Gas phase synthesis also produces particles of high purity composed of non-porous primary particles with small 40 size, and relatively narrow size distribution [8].

Karhunen et al. [9] showed that flame spray pyrolysis (FSP) [10] can be used to synthesise pure and doped LTO nanoparticles. The particles were found to be about $100 \mathrm{~nm}$ agglomerates consisting of primary particles with high elemental and phase purity. The primary and crystallite sizes were observed to be about $4510 \mathrm{~nm}$. Furthermore, when silver precursor was added to the synthesis a uniform distribution of silver nanoparticles (about $1 \mathrm{~nm}$ in size) was observed on the surface of the LTO primary particles.

However, when these LTO nanoparticles were tested in a Li-ion half cell the specific capacity fell significantly short of the a commercial reference LTO. 50 Based on the findings of Kavan et al. [5] it was decided that the most likely reason for this was the very small crystallite size of the nanoparticles.

It is worth noting that there is a trade-off between capacity and current in the utilisation of intercalation electrodes in Li-ion batteries. Smaller crystallite sizes promote better performance at high current densities due to the shorter 55 Li-ion diffusion path and the higher active surface area. However, they also lead to less efficient utilisation of the intercalation sites due to higher ratio of surface to bulk atoms and stress caused by higher curvature at the crystallite surface.

As one of the advantages of the FSP synthesis is its simple one-step design a 
post-synthesis heat treatment step was undesired. Instead a high-temperature

flow reactor was added to the synthesis apparatus to encourage further growth of the crystallites. In this article the modified FSP set-up as well as the morphology, composition and electrochemical behaviour of the resulting nanoparticles are described.

\section{Methods and materials}

65 2.1. Synthesis

For the liquid precursor lithium acetylacetonate (Li-acac) and titanium tetraisopropoxide (TTIP) were dissolved in stoichiometric ratio (4:5) in an equal volume mixture of toluene and 2-ethyl hexanoic acid (EHN acid), resulting in a solution with a total metal concentration of $1 \mathrm{M}$. The silver doping was realised

70 by adding silver 2-ethyl hexanoate (Ag-EHN) directly into the precursor solution. The mass fraction of dopant metal was $4 \%$ of the calculated LTO mass. The chemicals were supplied by Sigma Aldrich and Strem Chemicals (see Table 1 in [9]) and used as supplied.

The standard FSP set-up for the synthesis of LTO was described by Karhunen 75 et al. 9]. A premixed methane-oxygen flamelet ignites the aerosolised precursor solution resulting in the formation of a high-temperature flame, with temperatures in excess of $2000 \mathrm{~K}$ [10]. The metallic precursor components will then nucleate and condensate to form primary particles of pure metals (e.g. silver) or oxides (e.g. $\mathrm{Li}_{4} \mathrm{Ti}_{5} \mathrm{O}_{12}$ ).

In the standard FSP process the quenching of the particle sintering is very efficient [1]. As such primary particle size remains small. However, it also stops the growth and ordering of the crystallite structures. This can lead to retardation of the Li-ion diffusion within the crystallites reported by Kavan et al. [5]. In order to promote further crystallisation a high-temperature vertical 85 flow tube furnace (ID $25 \mathrm{~mm}$, length $800 \mathrm{~mm}$ ) was inserted above the FSP flame (Figure 1). 


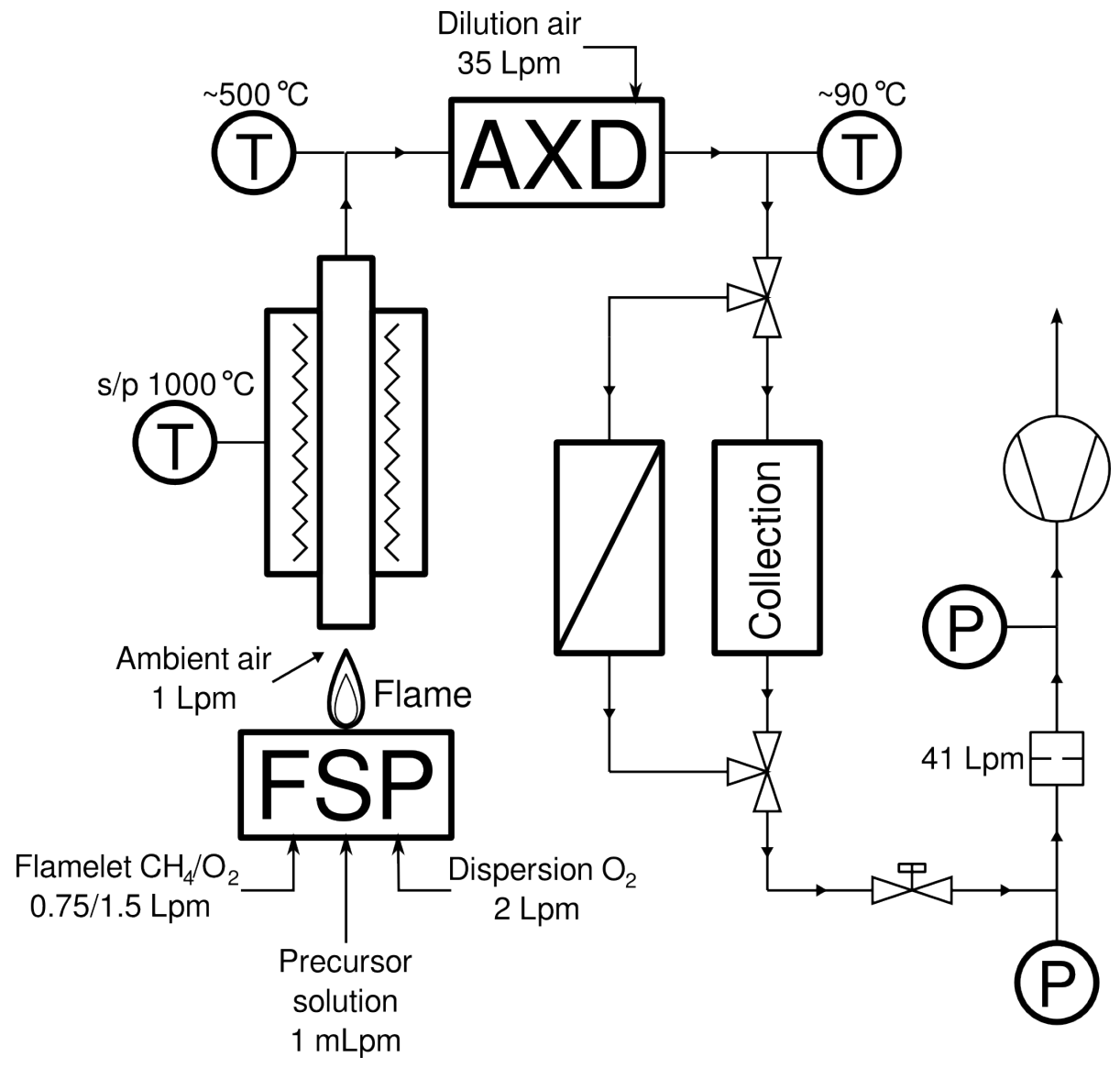

Figure 1: Schematic of the setup for $\mathrm{Li}_{4} \mathrm{Ti}_{5} \mathrm{O}_{12}$ nanoparticle synthesis with extended hightemperature residence. FSP: flame spray pyrolysis, AXD: axial diluter. 
The furnace set-point was maintained at $1000{ }^{\circ} \mathrm{C}$. This increased the hightemperature residence time from a few milliseconds to about $1 \mathrm{~s}$. However, it was noted that the furnace heating element turned on only occasionally during stable operation. This indicates that the heat generated by the flame was almost enough to maintain the set-point temperature at the mid point of the furnace.

The outflow from the furnace was rapidly quenched within an axial diluter (AXD) with $35 \mathrm{~L} / \mathrm{min}$ of dry, particle free dilution air. The dry product powder was then collected using a Teflon bag filter (Industri-Textil Job Oy). All material characterisation as well as the electrochemical testing was conducted on the collected powder as is.

\subsection{Analysis techniques}

X-ray diffraction (XRD) was performed on a Bruker AXS D8 Advance ( $\mathrm{Cu} \mathrm{K} \alpha$ source, $40 \mathrm{kV}, 40 \mathrm{~mA}$ ) and analysed with the Topas 3 software. The diffraction was measured between $2 \theta$ angles of 10 and $90^{\circ}$ with step size of $0.05^{\circ}$. The crystallite sizes, $\mathrm{d}_{\mathrm{XRD}}$, were calculated based on the fundamental parameter approach and the Rietveld method [12].

The particles were imaged with a field emission transmission electron microscopy (TEM, JEM-2100F, JEOL Ltd.), using acceleration voltage of $200 \mathrm{kV}$. Bright field (BF) imaging, selected area diffractometry (SAED), high angle annular dark field scanning TEM (HAADF-STEM) and energy dispersive X-ray spectrometry (EDS) were performed. To prepare the samples the powders were first dispersed into ethanol. An electron microscope sample grid (Agar Scientific), with perforated amorphous carbon supported on a copper mesh was then dipped into the dispersion and allowed to dry in room temperature before the imaging.

The electrochemical performance of the materials were tested using a multi channel battery tester (Maccor Inc.). The product powder was first sieved (45 $\mu \mathrm{m}$ cut-off) and dried overnight. An electrode slurry containing the active material (80 m-\%), PVDF (Kureha \#1100, 10\%), and conductive carbon (Timcal C65, 10\%) was prepared and doctor bladed $(150 \mu \mathrm{m}, 100 \mathrm{~m} / \mathrm{s})$ onto an 
Al-foil $(20 \mu \mathrm{m})$. The foil was then dried overnight at $120{ }^{\circ} \mathrm{C}$ in vacuum, and pressed in a calender.

Electrodes (14 mm diameter) were cut from the sheets and assembled into half-cells (CR 2016 type) with lithium counter electrode and glass fibre separator. The chosen electrolyte was $\mathrm{LiPF}_{6}$ in EC:DMC:DEC. These cells were then cycled between 1 and $3 \mathrm{~V}$ through a program of several constant current charge-discharge sequences. The current rates were chosen to correspond to the C-rates of $0.2,0.5,1,2,5$, and 10 . The resulting capacities were scaled with the active material mass to obtain specific capacity values for each C-rate.

\section{Results and discussion}

Pure and doped LTO nanoparticle were synthesised with the standard FSP method [10] by Karhunen et al. 9]. These particles (S-LTO) were found to consist of primary particles with high elemental and phase purity. The primary and crystallite sizes were observed to be about $10 \mathrm{~nm}$, indicating single crystalline composition. In the doped sample independently nucleated silver nanoparticles of about $1 \mathrm{~nm}$ size were observed on the surface of the LTO as primary particles.

The performance of these particles in a Li-ion secondary cell was, however, found to be inferior to that of a commercial reference LTO. The specific capacity for the pure LTO nanoparticles ranged from $93 \%$ (at $0.2 \mathrm{C}$ ) to $4 \%(10 \mathrm{C}$ ) of the capacity measured for the reference LTO, while the range was $85 \%$ to $32 \%$ for the silver doped sample.

The specific capacity measurements are summarised in Figure S1 in the supplement. It is worth noting that these capacity values are not directly comparable to those obtained for the LTO synthesised with the modified FSP set-up (HT-LTO) as the measurements were carried out by a third party using a different cell assembly and cycling program. However, it is possible to compare the performance by studying the capacities relative to the commercial reference $\mathrm{Li}_{4} \mathrm{Ti}_{5} \mathrm{O}_{12}$ (C-LTO) measurements carried out together with the S-LTO and HT-LTO measurements. 
The poor performance was probably due to the extremely small crystallite size of the S-LTO, detemined to be about $10 \mathrm{~nm}$. It is also worth noting that this crystallite size determined from XRD data is probably an overestimate; the XRD measurement tends to weight larger particles more due to the way the $\mathrm{x}$-ray radiation interacts with the crystallite planes.

Kavan et al. [5] showed that the optimum LTO crystallite size for Li-ion cell applications is about $20 \mathrm{~nm}$, about twice that obtained for the S-LTO. However, this optimum is only relevant for current densities (> 100C) greatly exceeding the typical operating conditions of the cells $(<10 \mathrm{C})$. They also found that for smaller particles sizes the the specific capacity falls off rapidly. Thus, it was deemed likely that the electrochemical performance of the FSP synthesised LTO could be increased by promoting crystallite growth.

To this end a vertical flow tube oven was added on top of the FSP flame (Figure 1) to increase the high-temperature residence time of the LTO particles. The resulting HT-LTO nanoparticles were found to have an average crystallite size of about $40 \mathrm{~nm}$ and consist almost entirely of $\mathrm{Li}_{4} \mathrm{Ti}_{5} \mathrm{O}_{12}$ (Figure 2), with a small amount of $\mathrm{TiO}_{2}$ impurity. The Miller indices for the main peaks of LTO spinel phase are listed at the top of the figure 3. The addition of the silver does not appear in the diffractogram due to its small concentration and crystallite 165 size (cf. $4 \% \mathrm{Ag}$ in Figure 5 of [9]).

However, the silver nanoparticles were observed in the TEM images. Figures $3 \mathrm{a}$ and $\mathrm{b}$ show bright field (BF) images of the pure and doped LTO particles, respectively. The two are very similar apart from small dark spots in the doped case, as highlighted by white arrows in Figure 3b. More detailed, highresolution images of the spots are provided as Supplementary data (Figure S2). When these images are compared with those of S-LTO (Figure 8 in 9]) it also is clear that the crystallites are more defined and larger in size, corresponding to the findings from the XRD data.

The distribution and elemental composition of the small spots were studied 175 in HAADF-STEM imaging mode combined with EDS (Figure 4. The HAADFSTEM image has typically poorer resolution than the BF, due to a lower signal 


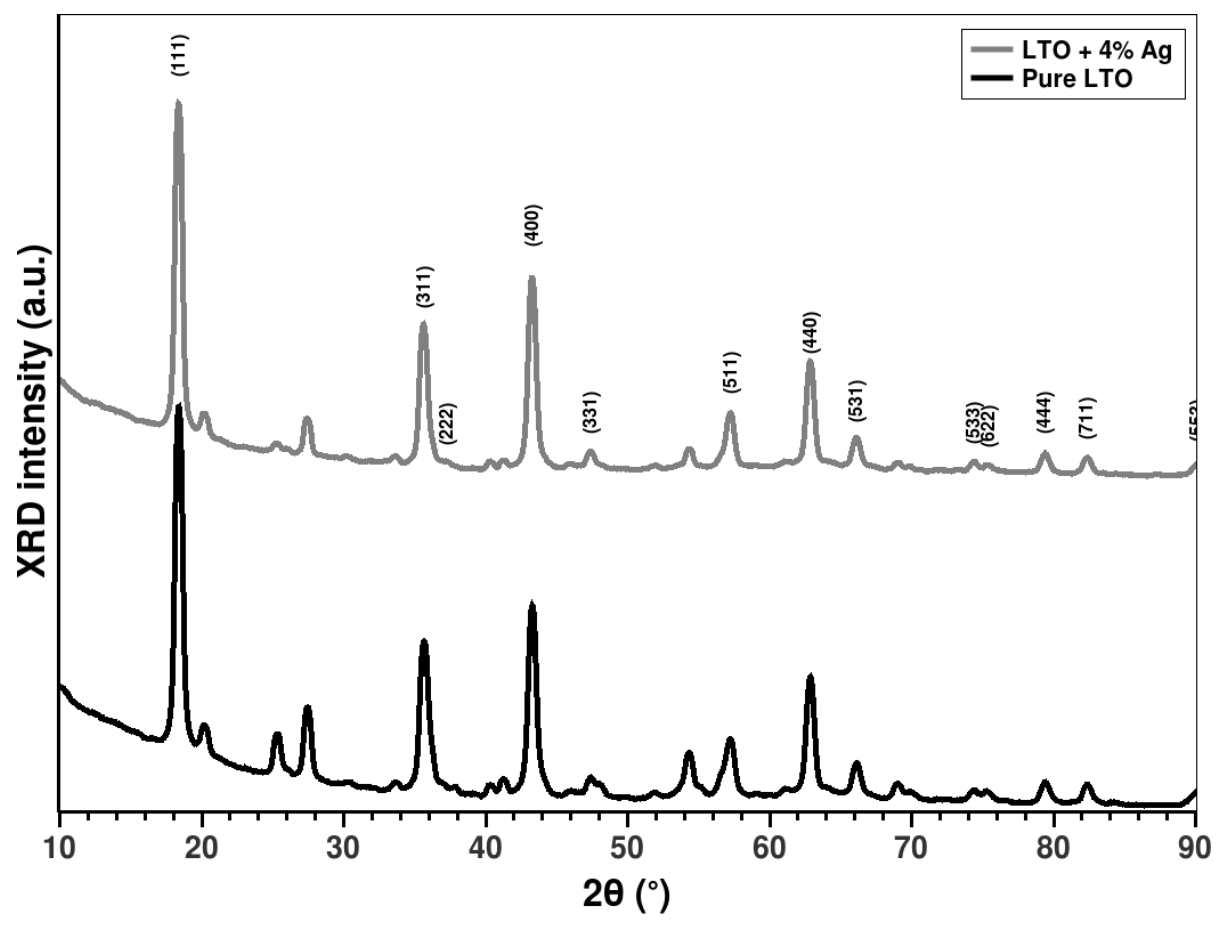

Figure 2: X-ray diffractograms of the pure and Ag-doped $\mathrm{Li}_{4} \mathrm{Ti}_{5} \mathrm{O}_{12}$ nanoparticles synthesised with extended high-temperature residence. The Miller indices of the $\mathrm{Li}_{4} \mathrm{Ti}_{5} \mathrm{O}_{12}$ lattice are indicated.
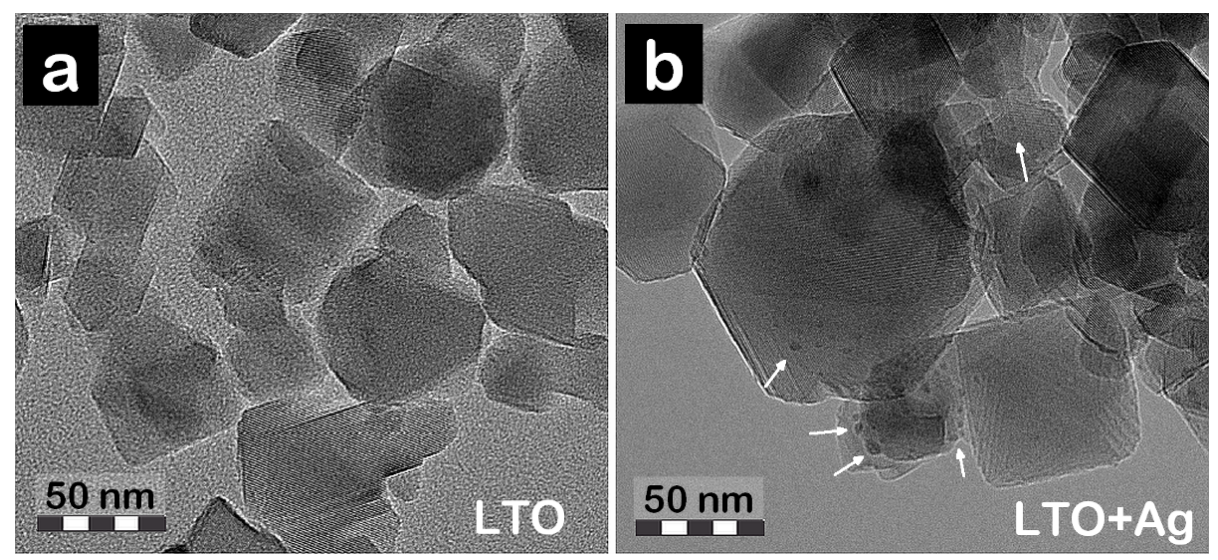

Figure 3: Bright field TEM images of crystallites of pure (a) and Ag-doped (b) $\mathrm{Li}_{4} \mathrm{Ti}_{5} \mathrm{O}_{12}$. Few of the silver nanoparticles observed in (b) are highlighted with white arrows. 
rate contributing to the image. It is, however, useful for showing differences in elemental composition between lighter and heavier elements as the image contrast is a function of atom number (approximately as $\mathrm{Z}^{2}$ ).

Figure $4 \mathrm{p}$ shows that the light spots, corresponding in size to the dark spots in the BF images, were found distributed across the surface of the LTO particles in the doped LTO sample (magnified image available in the supplement, Figure S3). The spots are absent in Figure 4 a supporting the observations on the BF images.

The spots observed in the doped LTO sample were verified as silver by acquiring energy dispersive X-ray spectrograms from equally sized areas (white circles in Figures $4 \mathrm{a}$ and b). The resulting spectrograms are shown in Figure 4 c. The silver $\mathrm{L} \alpha_{1}$ peak at $2.98 \mathrm{keV}$ was identified only in the spectrogram of silver doped LTO.

The crystalline structure of the samples were determined by acquiring electron diffraction patterns (DP) from selected areas. Multiple single LTO crystals result in randomly oriented diffractions, forming ring patterns as shown in Figure $5 \mathrm{a}$ and $\mathrm{b}$. An intense diffraction requires a high number of mutually oriented diffracting planes. The BF and HAADF-STEM analyses showed that the silver particles were very small compared to the LTO crystals, and thus clear diffraction signals from the silver crystals were not easily identifiable in the diffraction patterns.

On the other hand, the diffraction rings corresponding to lattice planes of $\mathrm{Li}_{4} \mathrm{Ti}_{5} \mathrm{O}_{12}$ are easily identifiable (Figure 5 ;). A diffractogram obtained by azimuthal integration of the DP intensity (Figure $5 \mathrm{~d}$ ) is in good agreement with that measured by XRD for bulk sample (Figure 2).

The electrochemistry of the material was studied by means of constant current charge-discharge cycling. The resulting discharge capacities for the various currents are plotted against the cycle number in Figure 6. Here, it can be seen that the doped nanoparticles posses the best performance, exceeding a comercially available reference $\mathrm{Li}_{4} \mathrm{Ti}_{5} \mathrm{O}_{12}$ (C-LTO), particularly at high C-values. On the other hand, the undoped nanoparticles roughly match the performance of 

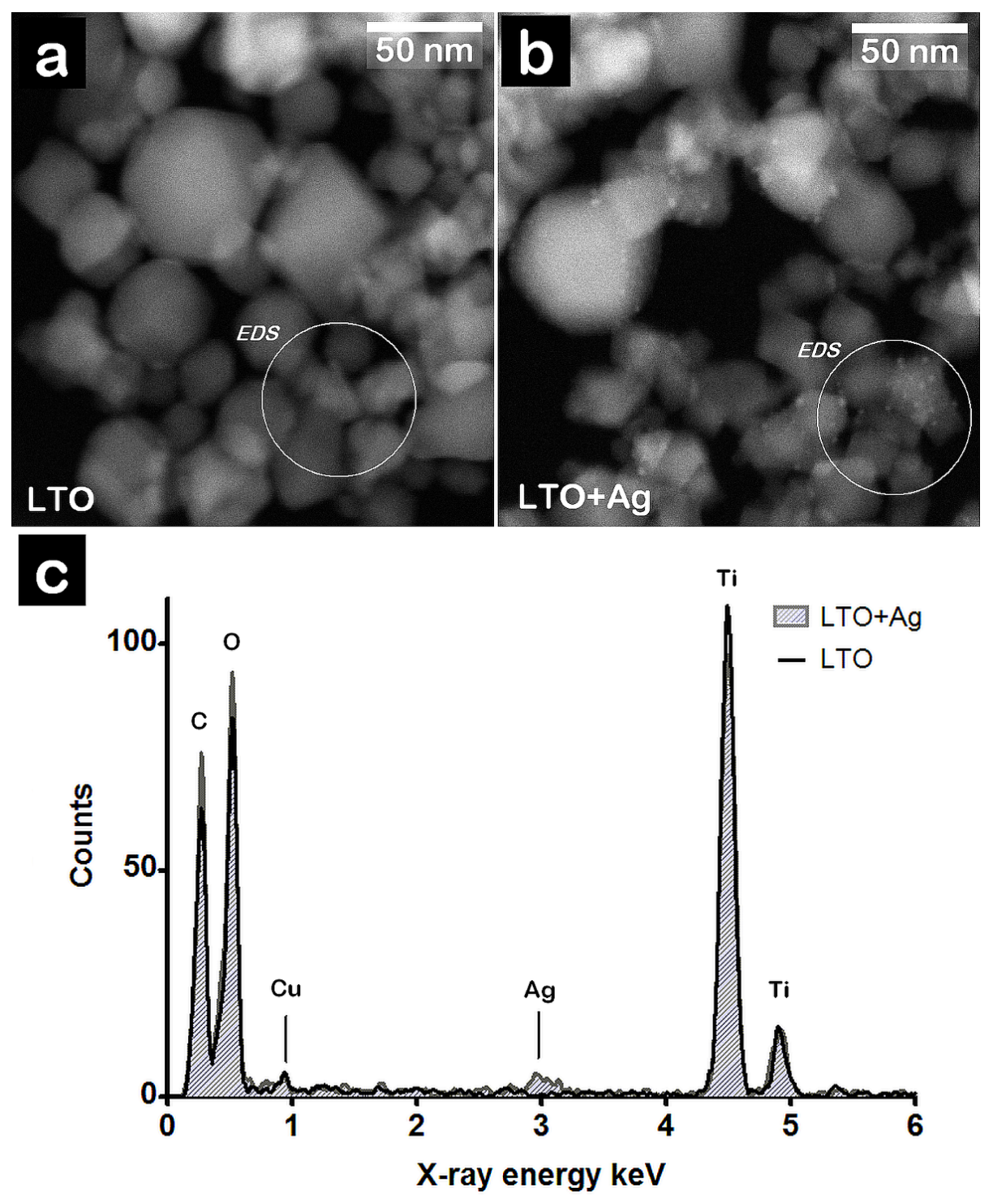

Figure 4: HAADF-STEM images of the pure (a) and Ag-doped (b) $\mathrm{Li}_{4} \mathrm{Ti}_{5} \mathrm{O}_{12}$, and the energy dispersive X-ray spectrograms (c) acquired from the areas marked with white circles in (a) and (b). A silver peak was identified in the X-ray spectra of the doped sample. 


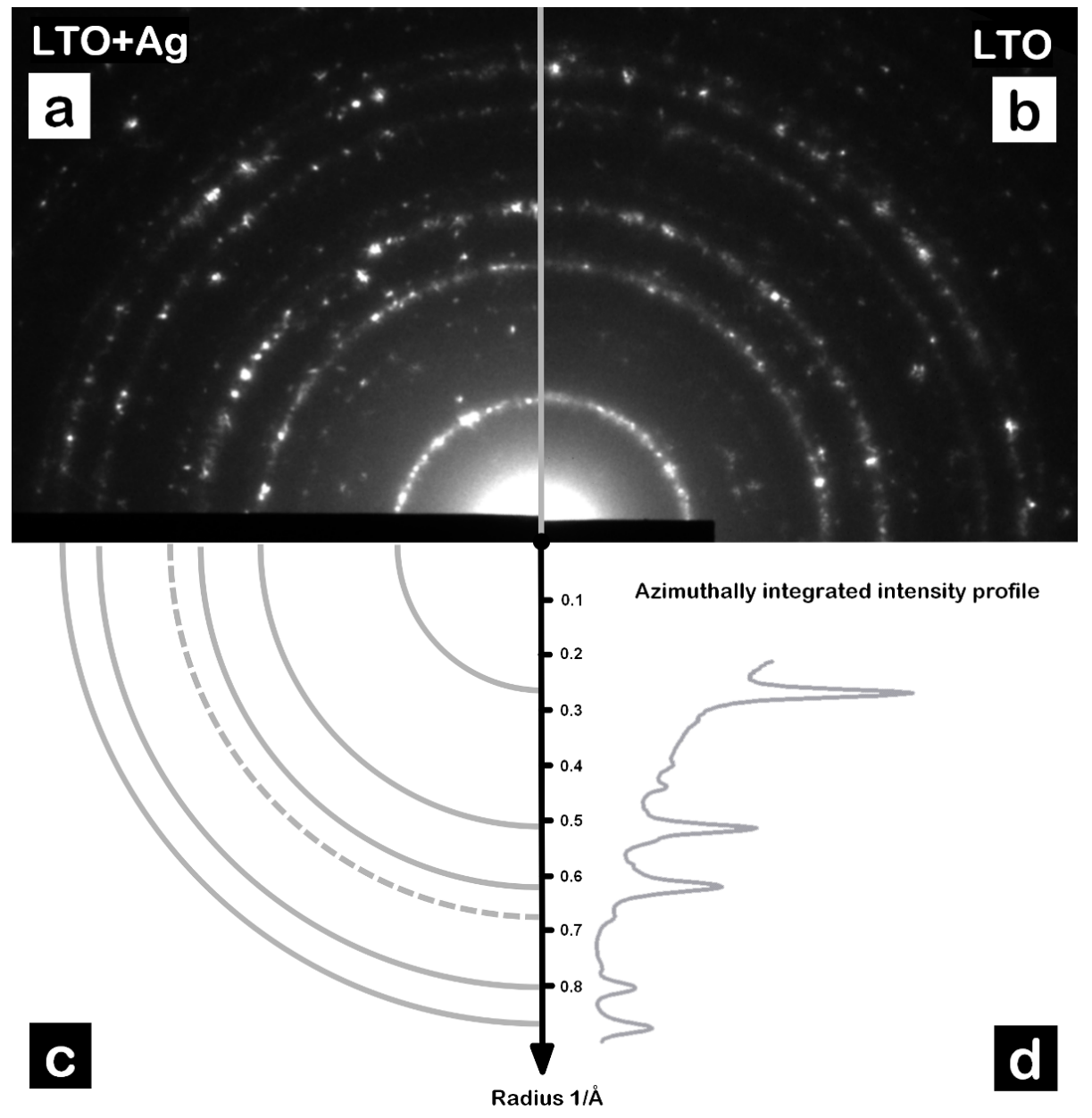

Figure 5: Selected area diffraction from Ag-doped (a) and pure (b) $\mathrm{Li}_{4} \mathrm{Ti}_{5} \mathrm{O}_{12}$. Lattice planes of the $\mathrm{Li}_{4} \mathrm{Ti}_{5} \mathrm{O}_{12}$ marked in (c) correspond to the intensity profile of the DP, integrated over $2 \pi$ radians $(d)$. The centre peak was removed from the intensity profile for clarity. 


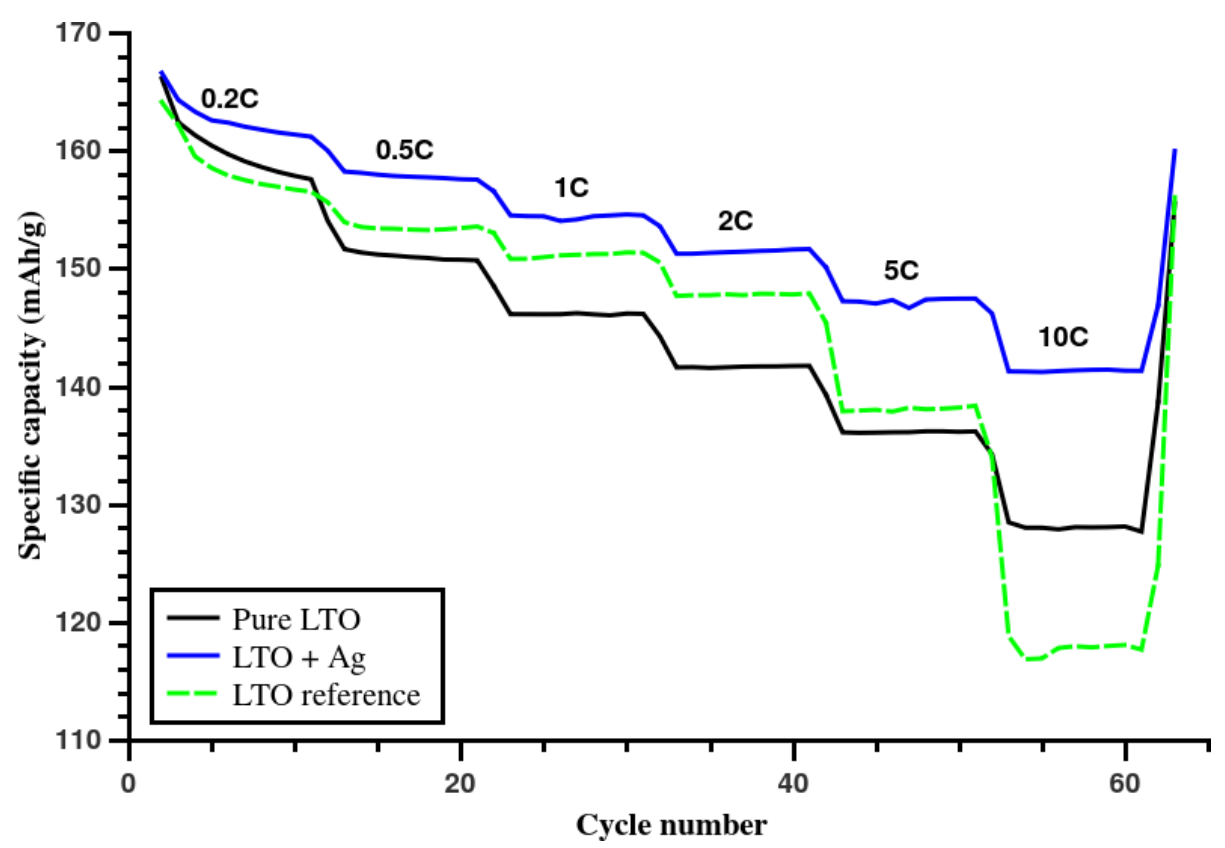

Figure 6: Evolution of the specific capacity of half-cells assembled with the high-temperature sysnthesised $\mathrm{Li}_{4} \mathrm{Ti}_{5} \mathrm{O}_{12}$ samples and the commercial reference. The cells were cycled 10 times at each C-rate (shown above the graph), with an initial formatting cycle at $0.1 \mathrm{C}$ and a final recovery test cycle again at $0.2 \mathrm{C}$.

the reference up to $5 \mathrm{C}$; while at $10 \mathrm{C}$ the capacity of the reference falls off much more rapidly than that of the HT-LTO nanoparticles.

Figure 7 shows the electrochemical performance of the pure and doped HTLTO nanoparticles compared to those of the reference material. From these results it is clear that the high-temperature synthesised LTO improves the electrochemical performance of the LTO nanoparticles.

The performance at low current values matches those of the reference LTO. This indicates a good accessibility of the Li-ion intercalation sites within the crystallites. With increasing current densities the capacity of the undoped HTLTO decreases roughly in-line with the C-LTO up to a C-rate of 5. However, at 10C the capacity of the nanoparticulate LTO exceeds that of the the reference by about $6 \%$. This reversal comes about due to the shorter Li-ion diffusion path 


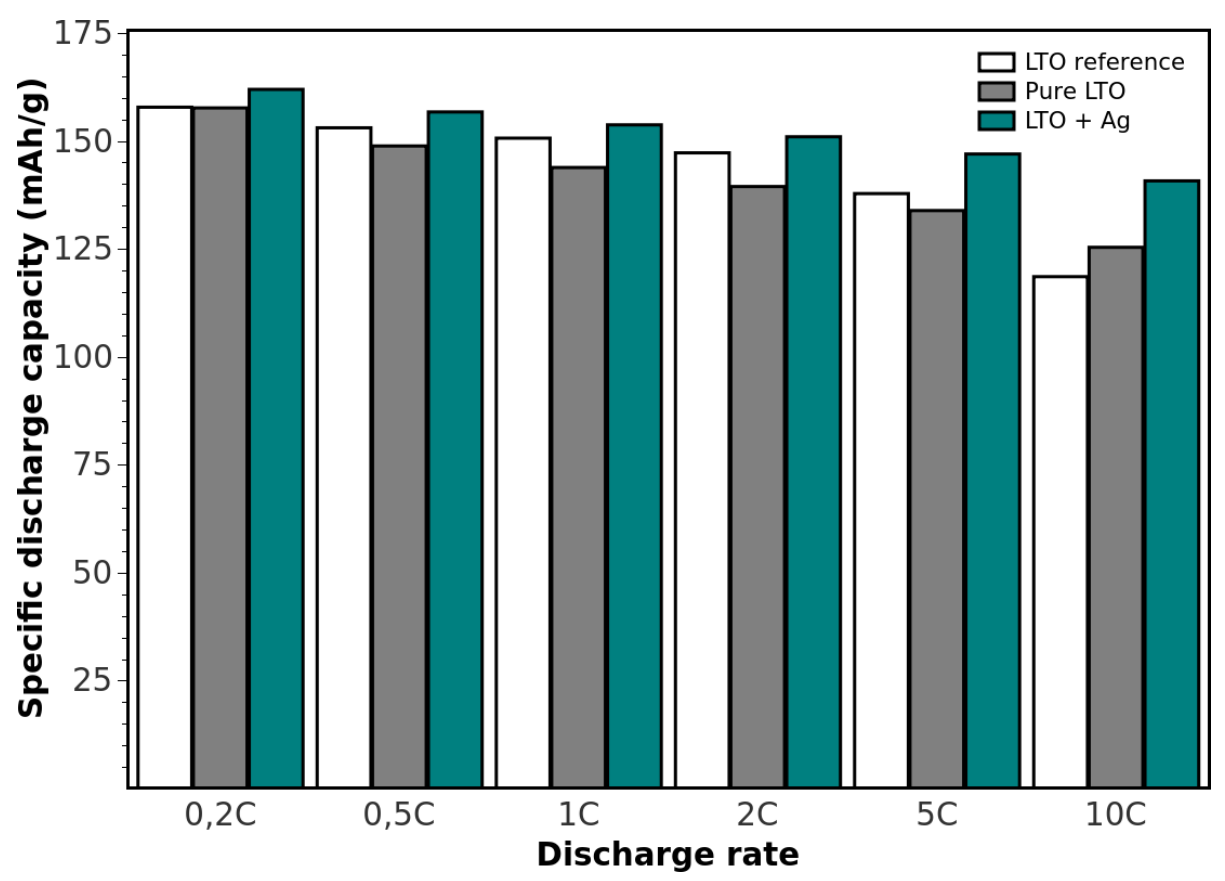

Figure 7: Specific capacity for $\mathrm{Li}_{4} \mathrm{Ti}_{5} \mathrm{O}_{12}$ nanoparticles synthesised using the modified FSP setup and cycled within a Li-ion half cell. The cells were cycled 10 times at each C-rate with the specific capacities averaged; $1 \mathrm{C}$ corresponds to a charge/discharge rate of $175 \mathrm{~mA} / \mathrm{g}$. 
lengths within the nanoparticles.

For the silver doped HT-LTO the increase in the capacity is even more evident (Figure 7). This improvement increases with increasing current densities from about $3 \%$ at $0.2 \mathrm{C}$ to about $19 \%$ at $10 \mathrm{C}$. This enhancement in performance can be attributed to a better electrical conductivity of the LTO material provided by the Ag-doping. The higher conductivity becomes particularly important for high current operation.

\section{Conclusion}

It was shown by [9] that pure and silver doped $\mathrm{Li}_{4} \mathrm{Ti}_{5} \mathrm{O}_{12}$ nanoparticles can be synthesised using the standard flame spray pyrolysis method. However, these particles exhibited poorer than expected electrochemical performance when used in Li-ion half cells. The likely cause of the poor performance was determined to be the extremely small crystallite and primary particle size of the product.

To overcome the performance limitation a modified FSP system was designed to encourage growth of the crystallites. This was achieved by adding a vertical flow furnace into which the combustion gases from the FSP flame were drawn. The furnace was maintained at $1000{ }^{\circ} \mathrm{C}$ to extend the high-temperature residence time of the nanoparticles.

This high-temperature synthesised LTO was found to exhibit significantly improved specific capacity compared to LTO synthesised with the standard FSP method, especially at high current rates. Furthermore, the capacity of the HT-LTO matched or exceeded the performance of a commercial reference LTO powder.

With a silver doping the HT-LTO nanoparticles provided even better electrochemical performance, exceeding that of the reference material by $19 \%$ at a C-rate of 10. This high performance at high currents can be attributed to a combination of the short diffusion paths due to the small primary particle size and to the improved conductivity of the material due to the silver doping.

Thus it can be concluded that to obtain the best performance for LTO 
nanoparticles by FSP synthesis steps need to be taken to achieve a crystallite

\section{References}

[1] P. J. Hall, E. J. Bain, Energy-storage technologies and electricity generation, Energy Policy 36 (12) (2008) 4352-4355. doi:10.1016/j.enpol. 2008.09 .037

275

[2] A. du Pasquier, I. Plitz, S. Menocal, G. Amatucci, A comparative study of Li-ion battery, supercapacitor and nonaqueous asymmetric hybrid devices 
for automotive applications, Journal of Power Sources 115 (1) (2003) 171178. doi:10.1016/S0378-7753(02)00718-8.

[3] T. Ohzuku, A. Ueda, N. Yamamoto, Zero-strain insertion materials of $\mathrm{Li}\left[\mathrm{Li}_{1 / 3} \mathrm{Ti}_{5 / 3}\right] \mathrm{O}_{4}$ for rechargeable lithium cells, Journal of the Electrochemical Society 142 (5) (1995) 1431-1435. doi:10.1149/1.2048592.

[4] A. S. Arico, P. Bruce, B. Scrosati, J.-M. Tarascon, W. van Schalkwijk, Nanostructured materials for advanced energy conversion and storage devices, Nature Materials 4 (5) (2005) 366-377. doi:10.1038/nmat1368.

[5] L. Kavan, J. Prochazka, T. M. Spitler, M. Kalbac, M. Zukalova, T. Drezen, M. Gratzel, Li insertion into $\mathrm{Li}_{4} \mathrm{Ti}_{5} \mathrm{O}_{12}$ (spinel), Journal of the Electrochemical Society 150 (7) (2003) A1000-A1007. doi:10.1149/1.1581262.

[6] S. Huang, Z. Wen, J. Zhang, X. Yang, Improving the electrochemical performance of $\mathrm{Li}_{4} \mathrm{Ti}_{5} \mathrm{O}_{12} / \mathrm{Ag}$ composite by an electroless deposition method, Electrochimica Acta 52 (11) (2007) 3704-3708. doi:10.1016/j. electacta.2006.10.044.

[7] D. Wang, H.-Y. Xu, M. Gu, C.-H. Chen, $\mathrm{Li}_{2} \mathrm{CuTi}_{3} \mathrm{O}_{8}-\mathrm{Li}_{4} \mathrm{Ti}_{5} \mathrm{O}_{12}$ double spinel anode material with improved rate performance for li-ion batteries, Electrochemistry Communications 11 (1) (2009) 50-53. doi:10.1016/j. elecom.2008.10.029

[8] H. K. Kammler, L. Mädler, S. E. Pratsinis, Flame synthesis of nanoparti$\square$ cles, Chemical Engineering and Technology 24 (6) (2001) 583-596. doi: 10.1002/1521-4125(200106)24:6<583: :AID-CEAT583>3.0.CO;2-H

[9] T. Karhunen, A. Lähde, J. Leskinen, R. Büchel, O. Waser, U. Tapper, J. Jokiniemi, Transition metal-doped lithium titanium oxide nanoparticles made using flame spray pyrolysis, ISRN Nanotechnology 2011 (2011) ID 180821. doi:dx.doi.org/10.5402/2011/180821. 
[10] L. Mädler, H. K. Kammler, R. Mueller, S. E. Pratsinis, Controlled synthesis of nanostructured particles by flame spray pyrolysis, Journal of Aerosol Science 33 (2) (2002) 369-389. doi:10.1016/S0021-8502(01)00159-8.

[11] R. Strobel, S. E. Pratsinis, Flame aerosol synthesis of smart nanostructured materials, Journal of Materials Chemistry 17 (2007) 4743-4756. doi:10. 1039/B711652G.

[12] R. W. Cheary, A. Coelho, A fundamental parameters approach to X-ray line-profile fitting, Journal of Applied Crystallography 25 (2) (1992) 109121. doi:10.1107/S0021889891010804. 

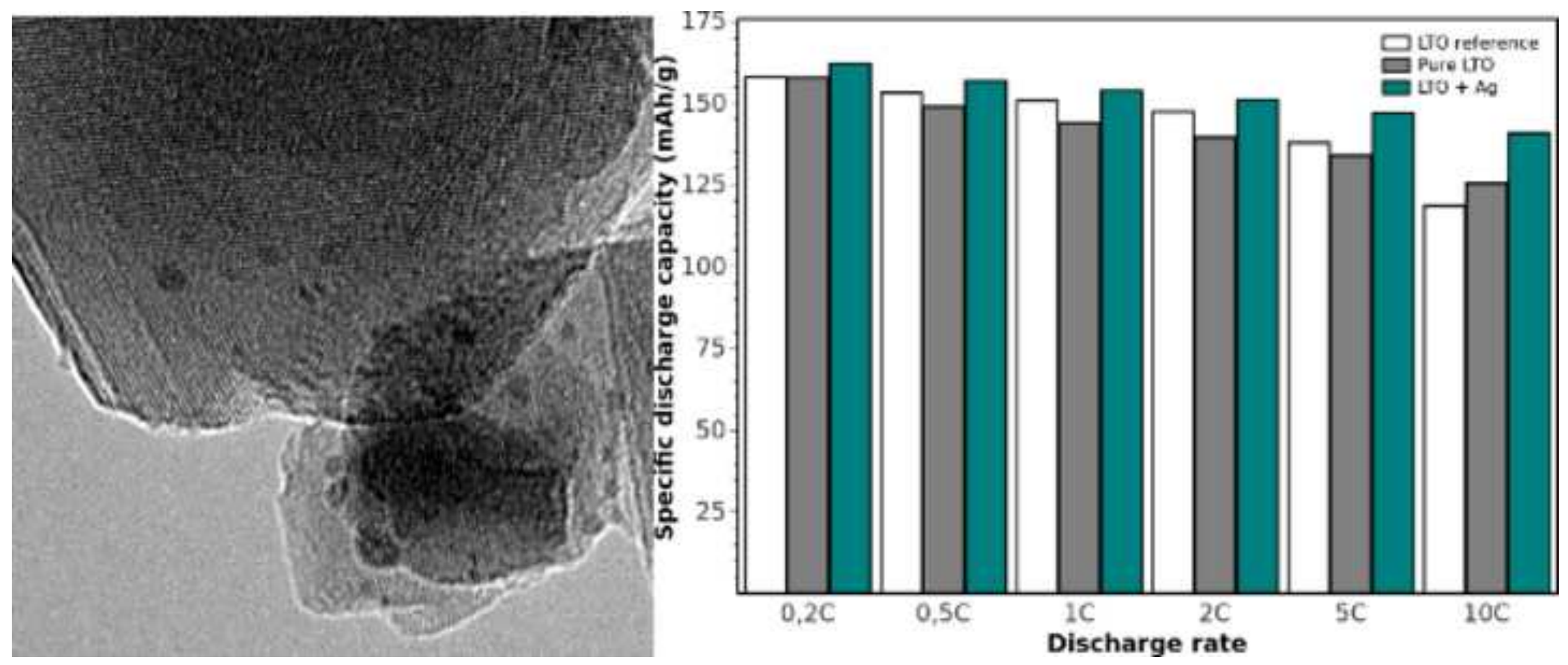


\title{
Effect of doping and crystallite size on the electrochemical performance of $\mathrm{Li}_{4} \mathrm{Ti}_{5} \mathrm{O}_{12}$ : Supplement
}

\author{
Tommi Karhunen ${ }^{\mathrm{a}, *}$, Juho Välikangas ${ }^{\mathrm{b}}$, Tiina Torvela ${ }^{\mathrm{a}}$, Anna Lähde ${ }^{\mathrm{a}}$, Ulla \\ Lassi $^{\mathrm{b}, \mathrm{c}}$, Jorma Jokiniemi ${ }^{\mathrm{a}}$ \\ ${ }^{a}$ University of Eastern Finland, Fine Particle and Aerosol Technology Laboratory, \\ P.O.Box 1627, FI-70211 Kuopio, Finland \\ ${ }^{b}$ University of Jyväskyla, Kokkola University Consortium Chydenius, \\ Talonpojankatu 2B, FI-67100 Kokkola, Finland \\ ${ }^{c}$ University of Oulu, Research Unit of Sustainable Chemistry, \\ P.O.Box 3000, FI-90014 Oulu, Finland
}

*Correspondence to tommi.karhunen@uef.fi 


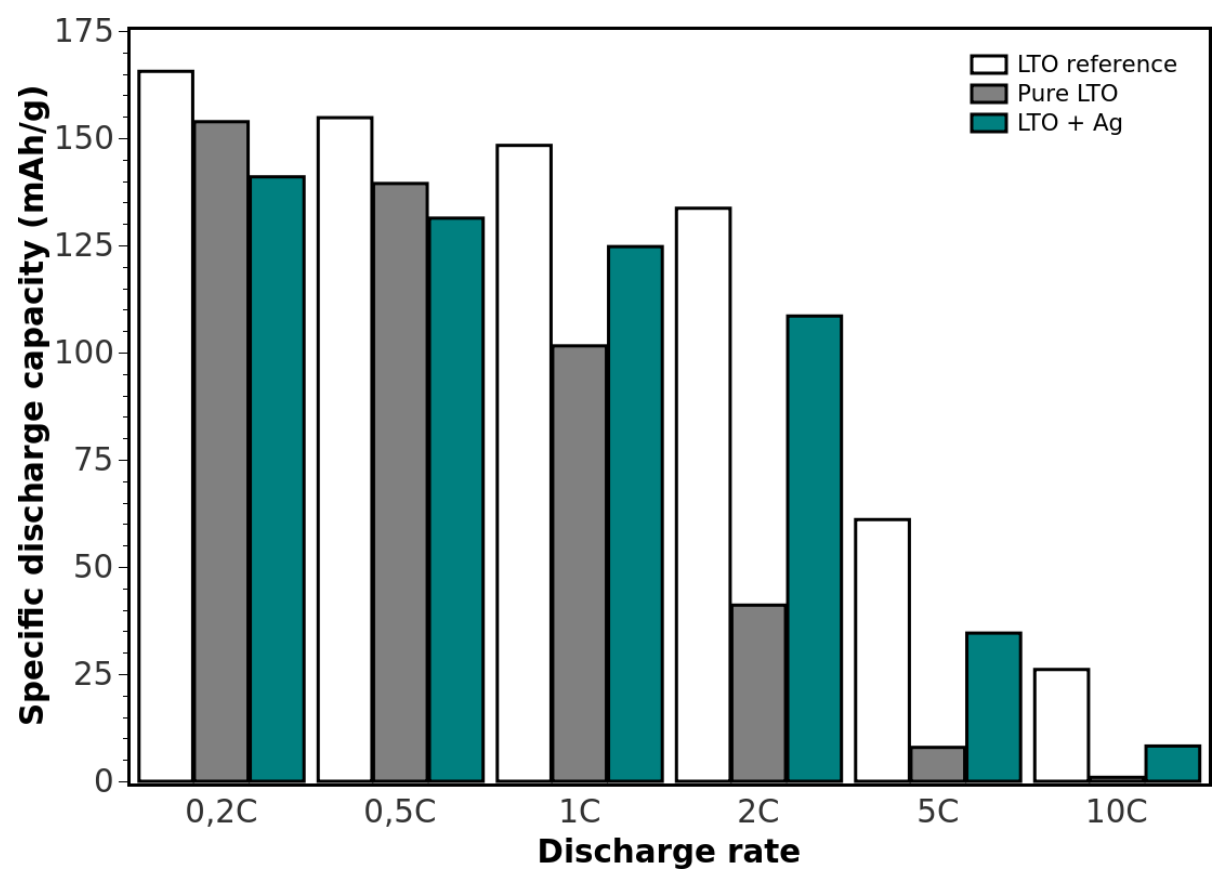

Figure S1: Average specific capacity for $\mathrm{Li}_{4} \mathrm{Ti}_{5} \mathrm{O}_{12}$ nanoparticles synthesised using the standard FSP setup and cycled within a Li-ion half cell. The rapid drop of the capacity for higher currents resulted from poor optimisation of the cell assembly. 


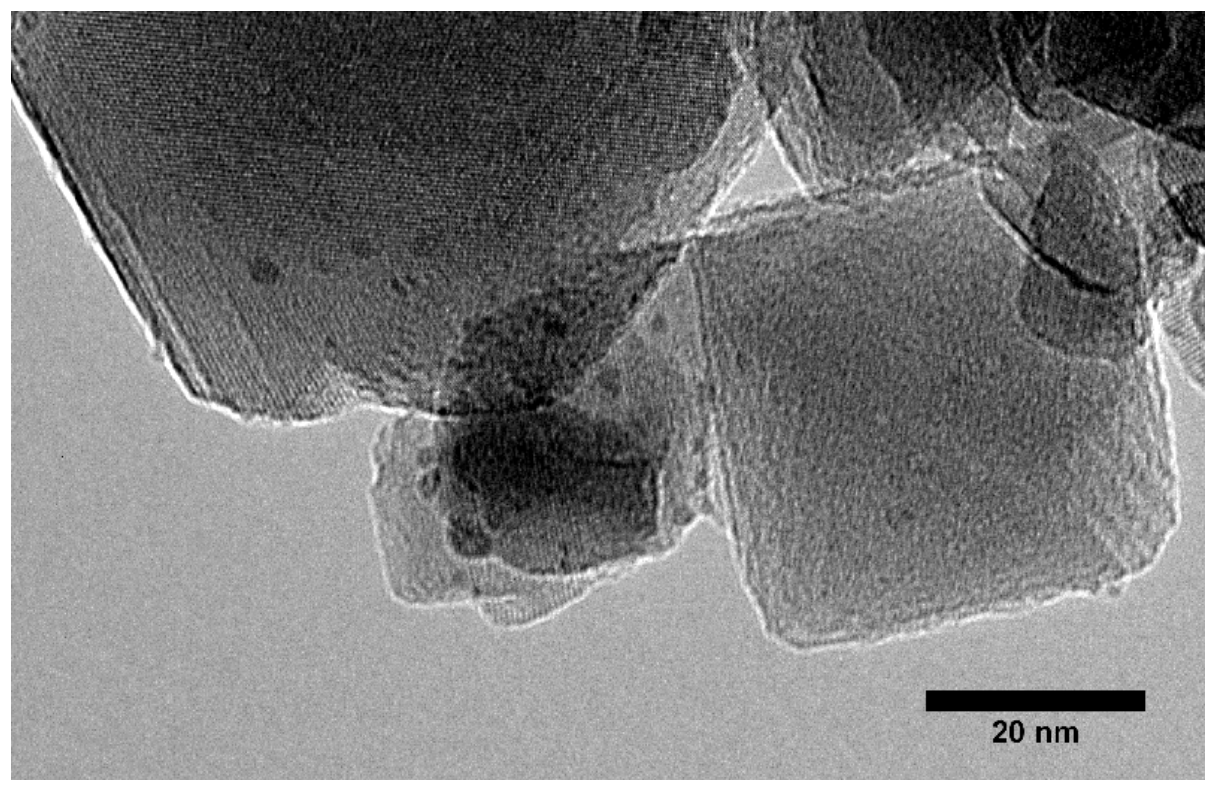

Figure S2: Higher magnification TEM slide of the silver particles attached to the surface of the LTO crystallites in Ag-doped LTO nanoparticles. The size of the silver particles is only about $2.5 \mathrm{~nm}$, (as measured from the image) compared to the LTO crystallite size of $40 \mathrm{~nm}$ (as determined from XRD data). 


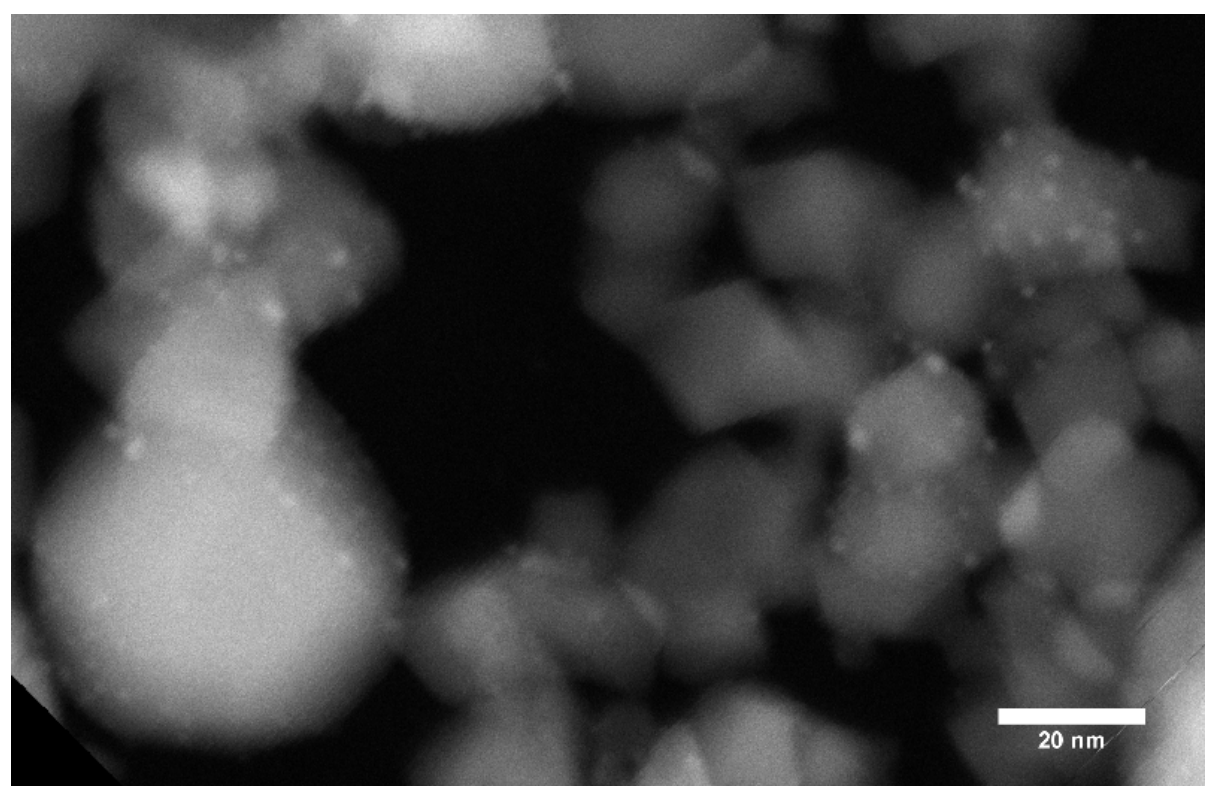

Figure S3: Higher magnification HAADF-STEM image illustrating the distribution of the silver particles across the surfaces of the larger LTO crystallites. While the image resolution is poorer compared to BF-TEM images, the enhanced mass contrast was used to highlight the heavier elements in the image. 